\title{
Consumer decision-making for functional foods: Insights from a Qualitative Study
}

\author{
ABSTRACT \\ Purpose \\ This study examines functional foods, a relatively recent development in the food \\ industry, from the perspective of consumer decision-making. It deals specifically \\ with consumers' attitudinal dispositions towards such products and seeks an overall \\ comprehension of the elements of decision-making factors that precede their \\ purchase. \\ Design/ Methodology \\ This exploratory work methodologically utilises several elements of a grounded \\ theoretical approach, in-depth interviews with consumers (and food industry experts) \\ and, more importantly, the constant comparative method of analysis. \\ Findings \\ The analysis indicates that three levels of decision-making processing form \\ consumers' final functional food choices in either affirmative or negative ways. At \\ the abstract level, consumers position functional foods within their food system. A \\ 'benefit negotiation' process acts as the central route of decision-making. Finally, \\ during the 'appraising' stage a representation of each functional food is built. This \\ representation should not be perceived as a rigid one as it can be influenced by \\ personal characteristics, marketing activities and, more importantly, monetary \\ considerations. \\ Originality/Value \\ The paper proposes a decision-making framework that takes choice issues into \\ consideration. It builds on (connecting and challenging) some of the existing \\ consumer literature on functional foods. The findings indicate the dynamic nature of \\ consumers' decision-making which is shaped by motivational and other personal \\ factors. The study identifies the concept of perceived efficacy of such foods, a concept \\ discussed widely in previous literature, as a subordinate aspect when compared to \\ consumers' consumption motivation, perceived importance and perceptions of \\ pricing. The paper discusses the implications for theory, research and practice. \\ Key words: Functional foods; exploratory study; consumer decision-making; \\ attitudes; perceived efficacy.
}




\section{Consumer decision-making for functional foods: Insights from a Qualitative Study INTRODUCTION}

Some recent socio-economic trends and changing consumers' lifestyles, including an aging population, the rising acceptance of connections between health and diet and consumers' lack of time and constant search for convenience, have increased the demand for foods that can be perceived as nutritious. The sharp advancements in food research and technology (Siro et al., 2008) have facilitated the development of a specific food category, tailored to satisfy the aforementioned social trends, namely functional foods. Functional foods have been introduced in the market place based on the premise that compared to conventional foods, these help to ensure the improvement of specific health conditions in a convenient way.

For marketing purposes an examination of consumers' reactions to functional foods has been evaluated as the main driver of their future acceptance and development (Bech-Larsen and Scholderer, 2007). Academically, this product category can be placed within a wider system of food choices, perceptions of healthiness and sociology of eating that renders them an ideal context for social research. The aim of this paper is to provide a deeper understanding and extension of the existing literature and position this into a consumer decision-making framework.

\section{REVIEW OF THE TERM FUNCTIONAL FOOD}

Although a definition of functional foods is missing even at a legislative level, a classification which embraces the following characteristics: (a) a food which can be consumed as part of a normal diet (not a drug or a capsule) (agreed by industry experts); (b) a food which is satisfactorily demonstrated to affect beneficially one or more target functions in the body, beyond adequate nutritional effects, in a way that is relevant to either an improved state of health and well-being and/ or reduction of risk 
of disease (Diplock et al., 1999, p. 6); and (c) a food which has gone through some kind of modification (fortification, enrichment, enhancement or removal) of some nutritional ingredients (agreed by industry experts) best describes the concept of functional foods as examined for the purposes of this study. This classification has been based on extended literature search (including market reports) and has been validated following discussions with food industry experts, interviewed for the purposes of this study. They have emphasised several aspects related to functional foods. They agreed that natural products (for example tomatoes are supposed to have anti-cancer properties) should not be included (expert 1, 2 and 3 have agreed with the processed nature of such foods). They also explained that the main characteristic to be emphasised is that of 'improvements in the state of the health or wellbeing' of the individual. In order for a functional food to be an excellent food product it needs to offer a specific health claim. This requires intense research and development efforts along with strong business strategic intent and planning.

\section{PREVIOUS RESEARCH}

Over the years a competent body of research in the field of consumer behaviour towards functional foods has approached the topic largely in terms of the following four areas:

1) the characteristics of functional food consumers (Childs and Polyzees, 1997; Anttolainen et al., 2001; de Jong et al., 2003; Saher et al., 2004;

Verbeke, 2005; Huotilainen et al., 2006; Horska and Sparke, 2007; Herath et al., 2008);

2) the relationship between health claims and base food products (carriers) (Bech-Larsen and Grunert, 2003; van Kleef et al., 2005; van Trijp and van der 
Lans, 2007; Siegrist et al., 2008; Lähteenmäki et al., 2010; Saba et al., 2010; Grunert et al., 2011);

3) consumers' knowledge, understanding and attitudes towards functional foods (Bhaskaran and Hardley, 2002; Bech-Larsen and Grunert, 2003; Ares et al., 2007; Niva, 2007; Barrios et al., 2008; Landström et al., 2009; Annunziata and Vecchio, 2011; Cornish, 2012);

4) motivational and other factors influencing willingness to use/ try or intention to consume functional foods (Cox et al., 2004; Jonas and Bechmann, 1998; Patch et al., 2005a and b; Verbeke, 2005; Urala and Lähteenmäki, 2003; 2004, 2007; Krystalis et al., 2008; Siegrist et al., 2008; O’Connor and White, 2010).

The way choices towards functional foods are shaped and especially attitudinal perspectives have been widely endorsed by relevant researchers.

\section{Characteristics of functional food consumers}

Research has generally sought one or the other of two kinds of consumer characteristics: the place of functional food purchasers' in the social structure and the personal dispositions of such consumers. The more common of the two is the quest for the socio-demographic characteristics of functional foods consumers: age, sex and education, for instance (Childs and Polyzees, 1997; Anttolainen et al., 2001; de Jong et al., 2003). Although generalizing the characteristics of a functional food user must be treated with great circumspection (De Jong et al., 2003), females in the 35-64 age group and in higher income groups are significantly more possible to be strong believers of the health benefits of functional foods (Childs and Polyzees, 1997; Anttolainen et al., 2001). Middle-aged and elderly consumers have been found to be 
more aware of health issues and tend to believe functional food claims because they or members of their immediate social environment are much more likely to be diagnosed with a lifestyle-related disease (Verbeke, 2005; Herath et al., 2008). In many cases these characteristics are further combined with influential attitudinal or motivational factors with a purpose to create a basis for market segmentation (Herath et al., 2008).

\section{Health claims and carrier products}

Several studies have attempted to establish the perceived compatibility between the base food product (carrier) and the health claims. Relevant literature examining such issues is far from consistent. Studies (Van Kleef et al., 2005) have found no significant interaction between health claims and carriers and this implies considerable flexibility in the design of functional foods. Most research nevertheless suggests that the willingness to buy functional foods (Siegrist et al., 2008), their perceived healthiness (Bech-Larsen and Grunert, 2003; Saba et al., 2010) and general attitudes towards the products (Bech-Larsen and Grunert, 2003) are based on the carrier product along with the health claim itself. Further, results (Bech-Larsen and Grunert, 2003; Siegrist et al., 2008) indicate that functional foods based on carriers perceived as healthy (e.g. yoghurt) are more likely to be accepted by consumers and that the existence of health claims results in higher ratings of overall perceived healthiness, but in most cases a small or moderate effect was identified (van Trijp and van der Lans, 2007). Other recent and interesting topics of study include the investigation of the way health claims affect consumer perceptions of other product attributes like naturalness or tastiness and the way consumers interpret the health claims (Grunert et al., 2011). No 'halo' effect was identified due to the health claim 
and actually a moderate to negative effect of the health claim to other product attributes was identified (Lähteenmäki et al., 2010).

Consumers' knowledge, understanding and attitudes towards functional foods

A major part of this literature considers beliefs and attitudes as possessing a highly subjective nature (Fishbein and Ajzen, 1975), that consumers are capable of understanding and explaining, focusing thus on the observable part of the attitudinal process (Moliner and Tafani, 1997). For this reason, while quantitative approaches have been utilised (Bech-Larsen and Grunert, 2003; Ares et al., 2007), qualitative ones have been favoured by many researchers (Bhaskaran and Hardley, 2002; Niva, 2007; Barrios et al., 2008; Landström et al., 2009; Cornish, 2012). Bhaskaran and Hardley (2002) explored consumers' beliefs and attitudes towards functional foods by means of focus groups in the USA. This early period report exemplified general issues of opinions and beliefs regarding functional foods (also Barrios et al., 2008). It was indicated that participants (both users and non users of functional foods) were rather sceptical of the claims. Nevertheless, users declared switching to functional foods based on the hope that the product might eventually have some kind of therapeutic power. Niva (2007) placed functional foods within the context of consumers' understanding of the connection between food and health. This study indicated that functional foods are more than products to be accepted or rejected. They can be more adequately perceived as a socially and culturally shaped phenomenon, understood and placed within the wider eating system of consumers (see also Crawford et al., 2011; Weiner, 2011).

The importance of consumer attitudes towards the base product and enrichment in the process of consumer acceptance of functional foods has been reported (e.g. Bech-Larsen and Grunert, 2003). A more recent study (Cornish, 2012) 
points to a more interesting finding; sometimes consumer perceptions that foods that contain nutrients are always healthier can result in unhealthy food choices just because these are accompanied by a health claim.

\section{Factors influencing intention to consume functional foods}

Other researchers have addressed cognitive, motivational and attitudinal determinants of consumer acceptance (Verbeke, 2005), willingness to use (Siegrist et al., 2008; Urala and Lähteenmäki, 2004, 2007; O’Connor and White, 2010) or intention to consume (Cox et al., 2004; Patch et al., 2005a; 2005b) functional foods in different countries. Urala and Lähteenmäki (2004) acknowledged a difficulty of the existing attitudinal scales to predict attitudes towards the distinctive functional characteristics, thus the aim of their research was to quantify the attitudes behind consumers' willingness to use functional products $(2004,2007)$. For this reason they established 53 food related statements (formulated on the basis of the results from a previous laddering study, Urala and Lähteenmäki, 2003). Four food-related attributes were found to be most indicative of consumers' willingness to consume functional foods and also were the most stable characteristics across both studies of 2004 and 2007 (Urala and Lähteenmäki, 2007): perceived reward, safety, confidence and necessity of functional foods.

Cox et al. (2004) and Patch et al. (2005a, 2005b) based their investigations on established theories which have found wide application in various disciplines and fields. The theory of planned behaviour (Ajzen, 1985), for instance, identified intentions to consume omega-3 enriched novel foods (Patch et al., 2005) and has been used to examine non users willingness to engage in a free functional product trial (O'Connor and White, 2010). Although this theory has been applied in explaining food choice in general (Anderson et al., 1998), its use in health related situations and 
functional foods analysis has been claimed to lack elements of the 'threat appraisal process'. This gap has been bridged by adapting the protection motivation theory (PMT) (Cox et al., 2004). PMT describes adaptive and maladaptive coping with a health threat as a result of two appraisal processes (Rogers, 1975 as in Cox et al., 2004), a process of threat appraisal and a process of coping appraisal. The model showed evidence of consistency within its constructs and explained a high 59-69\% of the variation of intention to consume imaginary functional foods targeting memory loss. The study demonstrated that perceived 'efficacy' of functional foods (followed by self-efficacy of the person who acts) against memory loss, is the most important determinant of intentions to consume.

\section{Perceived Efficacy}

Protection Motivation Theory is largely responsible for the inclusion of self and claim efficacy as widely applied concepts in health communications (Rogers, 1975; Madux and Rogers, 1983). The theory explains that any health communication provides the impetus for a person to access the (1) severity of an event or potential disease (2) probability of the event (or disease) occurring and (3) belief in the efficacy of the communicated solution or claim. Many health and nutrition related studies have taken this approach and have attempted to explore the contribution of these three dimensions on achieving the desired outcome. The results suggest that belief in the efficacy of the solution is a strong predictor of behavioural intention to adopt a specific suggested behaviour (Tanner et al., 1991; Cox et al., 2004).

A further finding has been the connection of perceived efficacy to the extent of processing of the relevant information or health claim (Block and Keller, 1995). The evidence suggests that less certain behaviours (low perceived efficacy situations) 
induce motivation to process a claim in much more detail and length compared to those perceived as high efficacy claims or health promises (Gleicher and Petty, 1992).

\section{Development of the new decision-making conceptual framework}

Following the above juxtaposition of literature, it is safely inferred that consumers' judgments are very much shaped through their own personal experiences and relationship with food in general (Niva, 2007), their cultural characteristics (Bech-Larsen and Grunert, 2003; Saba et al., 2010), but also the social constructs, formed through the industrial communication and treatment of functional foods until recently (e.g. van Kleef et al., 2005). In this study, participants' were offered the opportunity to express their own understanding of a wide-ranging direct and indirect experiences with functional foods that influence their decisions, investigating their knowledge, attitudes and personal reasons for both choice and rejection of such products.

Furthermore, although several aspects of consumer behaviour towards functional foods have been examined, the literature lacks a consistent framework which can explain how functional foods have been framed in consumers' mind and develop an understanding of the ways decisions regarding such products are formed. While previous research might have employed qualitative routes (e.g. Bhaskaran and Hardley, 2002; Niva, 2007; Crawford, et al., 2011; Weiner, 2011), none of these studies have benefited from the rich and holistic descriptions of correlated decisionmaking factors that the qualitative research can provide. An insight like that can facilitate a more efficient communication and targeting of such products and can set some light into reasons for choice and rejection at the same time (see figure II). 
The timely nature of a study in the UK food market can be additionally documented when briefly considering the existing market situation. Since 2007 there has been a healthy but slowing growth rate of the UK functional food market (an indication of market maturity) along with an increasing trend towards 'natural functionality' (Mintel, 2013). In addition, for several years countries were forced to develop local self-regulations on how the health effects can be accepted and communicated (ILSI, Europe, 2002), due to the absence of an EU wide list of claims. The European Food Safety Authority (EFSA) has been only recently (in May 2012) authorised 222 claims which are now exclusively approved for use by food and drink products. This meant that some highly 'marketable' claims like those of probiotic bacteria cannot be used any more. Although this is an improvement compared to the previous chaotic state, it introduced a new state of brands re-positioning their offerings.

Drawing on these observations the research objectives of this study have been: to fully describe the sophistication of functional foods decision-making process as valued by consumers. More specifically the aims are: to capture the vocabulary, knowledge base and attitudes of consumers regarding functional foods; to provide a deeper and extended understanding of the possible links between elements identified in the existing literature; to identify consumers' constructs and insights of the distinctive elements of functional foods decisionmaking process, and possibly place this process within a framework of a decisionmaking model (see figure III). 


\section{METHOD}

In order to address the purpose of the study, the grounded theory method was adopted (Berger and Luckman, 1966; Furst, et al., 1996; Charmaz, 2003). This approach differentiates this research from the existing literature by allowing for the exploration of consumer-based constructs and theories, including expression and integration of the factors that affect this multilayered phenomenon of functional food decision-making (Furst et al., 1996).

Fifteen personal interviews with a cross-section of consumers, acting in the UK food market, were conducted in order to understand consumer motivation and underlying reasons of behaviour. By no means, was this an effort to represent the population or food market consumers in general; contrary, it would be more legitimate to claim that a cross- section of people in the population was chosen in order to get broad patterns across a wide range of cases and a variety of views, in accordance with the exploratory nature of this research. In table I participants' characteristics are presented.

\section{-INSERT TABLE I ABOUT HERE-}

A purposive sampling (Flick, 2009:122) allowed for variation along the dimensions of age (ages ranging from 25-65 years), family situation (people living alone, living with a partner or having children at home) and role of functional foods in their household food system (occasional, frequent or non buyers/ users of functional foods). The majority of participants were administrative staff at a UK university and screening questions and snowballing practices in connection with the above characteristics were introduced to facilitate the process. A majority of the participants (12 out of 15) were actually responsible for the food buying decisions in their households. This is an acceptable quality for participants in food related studies, 
because people actively involved with the buying decisions can develop attitudes based on more pragmatic foundations and a better appreciation of the food market. Since this was an attempt to gain a variety of views, occasional buyers were not excluded.

The number of participants was predetermined and subsequently judged as adequate for the analysis purposes. Flexibility concerning this number was allowed, due to the estimated point of reaching saturation (Corbin and Strauss, 2008). All 15 interviews have been included in the analysis and it was marked that due to the sample's diversity, a feeling of theoretical saturation was attained. Theoretical saturation has been further reached due to the analysis process that is described in detail (see table II later this paper). The process of openly identifying the codes, defining, organising them in themes and identifying connections has contributed to the creation of all possible codes, the inclusion of the acceptable ones based on criteria and subsequently relationships identification has contributed to saturation.

In addition, in an effort to comprehend the industrial perspective of functional foods, four interviews with food industry experts (called Experts henceforth) were conducted. One R\&D executive (Expert 1), two Senior Product Managers (Experts 2 and 3) and one Marketing Manager (Expert 4) provided their valuable insights for the implementation of this study. Two interviews were conducted in person and the other 2 through video calls. These interviews possessed mainly a facilitating role and acted as an additional pool of ideas which enhanced researchers' knowledge. Their role has been supportive and thus abstracts have been used to expand on key arguments. The findings are incorporated throughout the analysis and not presented separately. 


\section{Materials and procedures}

All interviews were conducted during a two month period in order to reduce the impact of environmental influences (e.g. new functional product introductions, legal changes to the state of functional foods etc.). All 15 participants were interviewed in the relaxing atmosphere of their own setting (e.g. offices, homes) in order to minimize issues of anxiety and power (Stevenson et al., 2000). Each interview lasted approximately 40 minutes. They took the form of informal conversations, where opinions and ideas were shared a fact that was strengthened by the personal, focused and flexible (semi-structured) nature of the interviews (Kvale, 1996). An initial format of the interview guide was tested with two interviewees and several aspects were improved, concerning mainly the order of questions or phrasing.

Participants were encouraged to elaborate freely upon their experiences and ideas, stressing the fact that there are no correct or wrong answers. In an attempt to involve them with the topic of food choice, some elements and factors of their general food preferences were discussed. Respondents were then asked their understanding of the term functional foods and in all cases the classification (see the introduction of this article) was introduced. In addition, four stimuli products were presented (a drinking yoghurt enriched with Pre- and Probiotics, a box of cholesterol lowering cereals, an orange juice fortified with calcium — bearing the claim 'for healthy bones' - and a yoghurt brand enriched with an exclusive 'hunger control formula'). in order to assure that all participants had the same basic conceptualisation of functional foods. These products have only been used as general examples and no further emphasis has been placed during the interviews. The choice of the first two products is based on heart health and digestive claims being the two most profitable functional food categories according to Mintel (2013). The two additional products had been 
recently introduced in the market place at the time of interviews and have been chosen to widen consumers' perspective of the category. The questions regarding their underlying attitudes have been very much based on the only quantified attitude-related statements that were found to be the most influential of consumers' willingness to consume functional foods (Urala and Lähteenmäki, 2004; 2007): perceived reward, confidence/ necessity and safety of functional foods (example questions include: Do you feel people get some kind of reward through their consumption? What about yourself? What are your thoughts on the safety of such products? Are such products necessary? What role do such products serve in your diet?)

Functional foods' consumption or rejection was then brought to the fore. These questions generated a large amount of discussion and provided an in-depth understanding of participants' personal and indirect experiences with diverse functional foods (e.g. why do others consume functional products? What about yourself? What are some factors that you take into consideration when choosing such products?).

\section{Analysis}

All interviews were voice-recorded and then immediately transcribed, yielding five to six word-processed pages of transcribed data per interview. The next step was to get an overall impression of the interviews through multiple readings. The data were coded at three levels, open, axial and selective coding, as proposed by the constant comparative method (Glasser and Strauss, 1967; Corbin and Strauss, 2008). Themes were developed, the core theme along with possible relationships within and among categories were identified in order to achieve theoretical integration. The 
analysis process is fully presented along with the conceptual framework in the findings section.

This process has been a gradual work during and following the interviews and not a linear development as presented. As the research progressed, the categories were continually reviewed as further new data were collected.

Commencing this endeavour to develop categories that could explain the decision making process, it is crucial to state that the process generated is broad and will be exemplified as described by participants' general experiences and lay understanding of functional foods.

The framework developed is presented below:

\section{-INSERT FIGURE II HERE-}

Three processing levels (abstract level, benefit negotiation and final appraising) with several subcategories have emerged from the analysis as central for consumers' functional food decision-making. This process is diagrammatically presented in figure II, but should not be considered as an exact, linear procedure. Rather, the final decision of choosing or rejecting a functional product is shaped by the consideration of all the elements in the framework or even only one of them. The dotted lines of figure II denote that this process instead of being conceived as linear, is more dynamic and overlapping. At the highest abstract level, healthy eating values, which are often imposed externally (what the recent trends portray as healthy eating), act as a general guiding framework for the acceptance of functional foods. However, in most cases the relationship between this level and consumer choice seems to be mediated by the process of 'benefit negotiation', what has been identified as the core 
category of functional food decision-making. At this level, consumers seem to consider their perceived existing situation and form their own personal motivation for functional food choices. Marketing influences act mainly at the point of purchase and it seems that different consumers have different levels of resistance to marketing strategies.

The stages of data analysis are presented in table II:

\section{-INSERT TABLE II HERE-}

A very interesting case which will be further used to illustrate how some of the categories and their interactions have been developed could be indicated by using this abstract:

'I don't buy them (talks generally about functional foods)...but then you see these adverts with these women and flat stomachs and actually I would probably buy this one (shows a probiotic yoghurt)...but then you go to buy them and you perceive them as expensive and food that you don't really need...maybe when I get older...maybe then it's worth it ...hm (benefit negotiation process of future importance)'. (10, F, 25-39)

In the quotation above this informant talks generally about functional foods and elaborates for example on the following open codes: marketing influences (adverts, pricing) and pragmatic aspects (age). Selective coding is underlying the focus on the core area that is central in the data. Beyond the obvious focus on the decision-making, this analysis identified the level of 'benefit negotiation process' (with the open code of future importance above) as a core category where the main decision-making is taking place. Finally, axial coding is the level of finding connections among concepts. As this is an attempt to describe a basic psychological process, it falls into the 'process family' of axial coding (Glasser, 1978). The 
connections between the concepts is evident in the negotiation and appraisal process through the use of words like: 'perceive', 'maybe', 'worth it'.

This passage along with the developed framework clearly indicates the crux of the analysis;

Consumers' attitudes and perceptions of healthy eating act at an abstract level and are filtered through the second level of 'everyday' and 'psychological' considerations. Elements of everyday reality (e.g. being able to afford them, age) come into play with the images produced by self- relevant motives. This wrestle then finds a resort in appraisals and future projections.

This struggle indicates that the way consumers perceive functional food choices seem to have a dynamic of continually changing, depending on evolving individual motivations, facts of life (e.g. age, health) and the constructions of the social and environmental network (e.g. advertisement or what can be perceived as healthy eating).

Instead of names, participants have been characterized by a number ranging from 1 to 15; this identifiable number along with gender and age group accompany their abstracts.

\section{FINDINGS}

General knowledge of functional foods

As expected and indicated by the rest of the literature (Bhaskaran and Hardley, 2002; Barrios et al., 2008) a majority of the participants (11 out of 15) had never come across the term 'functional foods' and none of them could conceptualise exactly what the term could stand for. The most cited spontaneous responses have been 'fruits and vegetables that can help with functions in the body' (3, M, over 60; 9, M, 
25-39; 4, F, 40-59) and 'staples, like bread, milk, that you need to survive in everyday life' (5, F, over $60 ; 8, \mathrm{~F}, 40-59 ; 10, \mathrm{~F}, 25-39)$. As the aforementioned authors concluded, this situation can be justified given the fact that defining 'functional foods' has puzzled both scientists and the food industry, thus it came as no surprise that the participants had little understanding of this term.

Following the definition and the stimuli presentation, all participants easily cited several other products which could be considered functional. Participants of this study indicated that several aspects relevant to the characteristics of each product can influence their decisions but at the same time they could well conceptualise functional products as a group with some common characteristics and state a general opinion about them. Contrary, in the study by Barrios et al. (2008) participants' opinions reported to depend a lot on the type of products. The aforementioned grouped responses of participants could be subject to a bias caused by the definition used in this study.

\section{Decision-making process related to functional foods choices}

\section{Abstract Level of Decision-Making}

Perceptions of healthy eating: Healthy eating possesses a distinctive place in consumers' mind in recent years, a fact that was evident from the discussions. The positioning of functional foods in the healthy eating system depends on the diverse conceptualisations of what healthy eating is and the differing perceptions of 'consumers' food identity' which is based on personal eating habits. 'Healthiness' can be a wide term and participants described their understanding of this notion in different but common ways. 'Fruits and vegs' (e.g. 7, F, over 60; 11, F, 40-59) was the most common conceptualization of healthiness; others have been 'not heavy, fatty 
food' (12, F, 25-39), 'limited levels of fat or salt' (1, M, 25-39), 'fresh as opposed to processed food' (11, F, 40-59), 'made from ingredients I am familiar with' (7, F, over 60), 'low fat/ low calories' (2, F, 40-59). It is interesting to note however that the prominent UK ' 5 a day' slogan, although it actually refers to 5 portions of fruits and vegetables, was not in itself mentioned by any of the participants.

Three main categories of participants have been identified based on their diverse healthy food identities (all participants could be considered as roughly ranging across the following basic values). To begin with, some participants valued healthy eating and considered themselves as leading a healthy lifestyle and diet. They conceptualised healthiness in terms of freshness and considered anything processed as improper. They used heuristics to categorize functional foods as 'processed food' that they would not typically consume because 'if you have a balanced diet you don't really need them' (10, F, 25-39; 11, F, 40-59). Nevertheless, these same people allowed themselves occasionally to buy some of these products when on offer or depending on the specific product characteristics.

The subsequent category comprised of people who valued healthiness in general and could place functional foods within the boundaries of a healthy diet, when consumed in combination with other 'proper' food. It was not always the case that they choose to consume them, but they had developed more positive attitudes and intentions towards them. The two aforementioned categories considered that their own practices deviated from the 'norm' which in recent years has been connected to 'pleasure and convenience seeking habits' (13, M, 40-59). They further perceived that the consumption of functional foods can be very much connected (and convenient) for the final segment identified. This last group of people perceived their eating habits as unhealthy and used functional products to balance this situation. One 
participant (2, F, 40-59) stated: 'although I do not have a problem like those promised, I believe that it is probably better to consume those than ... other rubbish I tend to consume'. In that case consumers clearly connected functional foods to healthy eating, facilitated their functional food related decision and exonerated other food choices.

However it should be noted that no direct relationship between values of healthy eating and functional food choices can be reported. All participants could find a place for functional foods in their food system and at the attitudinal level they could report being negative or positive towards such products but when reporting their actual buying habits other considerations influenced their final decisions.

\section{$\underline{\text { Benefit Negotiation Process }}$}

Elements of the benefit negotiation process should be perceived as the central variables that influence consumers' choices. During this phase, the central benefit derived from functional foods is negotiated and placed within each personal life circumstances and relevance.

Pragmatic Aspects

Age-Gender-Health condition: The benefit negotiation process was mainly influenced by impressions of age and health condition. One young participant (14, F, 25-39) using an example from the immediate environment indicated how older people need such foods for prevention even when there is no real health necessity: 'well... I don't have a problem so I don't need to buy milk with low cholesterol or high calcium. My father uses cholesterol lowering spreads, he doesn't have a real problem but because he is older he feels he needs them for prevention'. Such ideas were common among participants of the 25-39 age group. At the same time, participants 
aged 60 and over identified their age group as more prone to consume functional foods and their own age as an important motivation for consuming them because of the health issues they face or might face in the future 'most of the people I know, I have to say, is probably people at my age group, including myself, who look at that sort of things, none of my children have any of these' (5, F, over 60).

Another male contributor of the younger age group (1, M, 25-39) admitted an impression that such products concern mainly women (for illnesses like osteoporosis). This participant also sensed that women are more interested and more willing to try new ideas and this is why he finds several products irrelevant to him. It is true that, as described by Expert 3, several of these products are originally developed for specific target markets; hence consumers seem to share a similar perspective with the industry experts.

Product characteristics form another broad category which not only influences the choice of functional products relatively to conventional ones; it also facilitates the choice of base product- claim combination and the choice among varieties of the same product. One of the first considerations is the base product. A female participant (8, F, 40-59) although indicated interest in a specific functional claim, stated that a choice of cereals is not appropriate for her as she dislikes cereals in general 'I don't like cereals in general. I have tried a load of them'. The decision to choose a specific base product was in many cases influenced by considerations of taste. For example 'I choose $x x x x x$ (mentions a specific brand of yoghurt) but just because I think it is great yoghurt, really tasteful' (6, F, 25-39). Throughout the interviews it has been a typical behaviour of participants to project decisions to the general population based on their own judgements. One participant (15, F, 25-39; 
also 4, F, 40-59; 1, M, 25-39) commented regarding taste 'some people never really pay attention to the claim but consume some products because they taste good... at least this is what I am doing'. However, taste could also have an adverse effect in the choice of functional foods. The added ingredients (like for example calcium) were perceived as possibly impairing the flavour of the functional product (11, F, 40-59).

Ease of use deals with aspects of required dietary daily changes in order to achieve maximum efficiency, for example: 'drinking a bottle of that (indicates a brand of drinking yoghurt)...every day is not easy. I might forget it or don't have the time for that. This can also affect the result that I am expecting from the product' (1, M, 25-39). This statement very much connects the efficacy of the product, the perceived importance of the benefit, monetary issues along with a product characteristic like incorporation in the daily routine.

Familiarity is another element that can influence choice. One participant (7, F, over 60) although indicated a negative general disposition towards such products, stated that the only functional product in her family fridge is cholesterol lowering spreads. Although initially she indicated ignorance of the reasons behind this choice she then stated 'it is just one of these things that has been around a long time and this has got into a psyche that this might be a good idea to use it'.

The category of 'product characteristics' is a reminder that functional foods are above all food products, thus some basic rules of food choice in general like superior taste, quality and variety are applicable to them also.

\section{Psychological Aspects}

'Self- related motivation. Going beyond a strict distinction between intrinsically and extrinsically motivated behaviour, this study identified two broad 
consumer motivations in terms of functional food need fulfilment: the basic need of eating combined with a need for hedonism and the attainment of a sense of self tranquillity and health safety (Bardi and Schwartz, 2003). Along these dimensions consumers self-relevant motives varied among participants and ranged from the health reward (5, F, over 60), easing 'guilt' for other food related choices (2, F, 40-59), disease prevention and fear for any health consequences of not using functional foods (14, F, 25-39) or basic hedonic aspects like superior taste or searching for convenience and a 'quick fix' (6, F, 25-39). One female participant identified no psychological benefits at all to be gained (11, F, 40-59).

Especially the health reward, an aspect which has gained a central role in previous research (see also Urala and Lähteenmäki, 2007) possessed a distinctive place in participants' discourses e.g. 'there are many health advantages to gain' (5, F, over 60; also 2, F, 40-59). Several statements clearly indicate that for some consumers functional foods consciously act as a compensation for other food-related choices. For example, preference to buy products with added calcium stems from their perceived and possible future calcium deficiency due to poor choices- 'he knows (her son) that he can probably develop calcium deficiency because he doesn't eat any dairy food at all. I also find this an important consideration and buy such foods for him' (5, F, over 60). Also, 'I would not sort of buying one with added calcium because I am consuming milk so in that sense I don't feel that I actually need that (10, F, 25-39)'.

All fifteen consumers of this study identified no actual harm to be caused by the use of functional foods (indicating that the processed nature of functional foods is not perceived as a disincentive for consumers). Some even accepted that the mere existence of such a category encourages people to take a more active stance when it 
comes to healthy eating 'encourage people to think in terms of their own health' $(6, \mathrm{~F}$, 25-39; also 12, F, 25-39). Functional foods have been also characterized as 'quality products' in the sense that more care and time has been taken from companies and laboratories to develop them (1, M, 25-39). At the other end, participants who found no real benefits to be gained through functional foods could be characterised by a great degree of consumer scepticism ('gimmick' (8, F, 40-59; 9, M, 25-39; 10, F, 2539), 'media hype' (7, F, over 60), 'cynical about the marketing' (13, M, 40-59), 'one is paying for the marketing' (13, M, 40-59)). Past research has indeed proved the emerging trend of consumer cynicism. Following this tendency many consumers might not perceive the benefits of functional foods because they might hold a general negative position towards marketing, anything new or simply the modern way of life: we survived years without them $(9, \mathrm{M}, 25-39)$.

The 'perceived efficacy' of such products which has been identified by previous research as a dominant factor of consumer choices (Cox et al., 2004) did not emerge as a central motivational element. Perceived efficacy was influenced by other consumption motivational aspects and especially perceived importance. Meaning that especially those in perceived need of functional foods based perceptions of positive efficacy on a hope that there are at least some chances that the benefits will be delivered (5, F, over 60; 2, F, 40-59 see also Bhaskaran and Hardley, 2002), 'I know I need it and I don't necessarily believe all they claim is marketing' (12, F, 25-39; 3, $\mathrm{M}$, over 60) or draw on their positive personal experiences and beliefs (e.g. 5, F, over 60). In several cases people alluded to 'big companies that I can trust' and 'branded products' (15, F, 25-39) or draw upon a vague attitude and conviction towards policy makers and the industry that 'I cannot see how they could claim something that is not valid?' (6, F, 25-39). When participants indicated a belief that such products cannot 
deliver their promises, they tended to justify their choices by focusing on other product characteristics 'I am not sure if it does what it is designed to do, but I just like it as a product (regarding a cholesterol lowering spread)' (1, M, 25-39) or other influences, like advertisement and offers (10, F, 25-39). In that sense, perceived efficacy which has acted in the past as a main variable (Cox et al., 2004) explaining consumers' intention to consume functional products, has not been included in this framework, as participants of this study tended to shape their understanding of efficacy in accordance with their motivation and importance and in that sense it was not found to influence their reported choices.

'Perceived importance' has been identified through data analysis to possess a central role in consumers' decision-making. The most important aspect is the significance consumers attribute to the core functional benefit for their own health and well-being. This can be conceptualised as a process where consumers assess the importance of a specific food and food benefit for their health—always in connection with the previously mentioned elements of the 'benefit negotiation' process and especially self-relevant motives. Increased perceived vulnerability from a disease is professed by participants to be a significant motivation that leads them to consume a functional product 'cholesterol lowering cereals I have had myself because I also take cholesterol tablets' (5, F, over 60; also 3, M, over 60). This relationship works also negatively, meaning that consumers, who did not feel threatened (due to age, gender, and other factors or simply due to 'optimistic bias' as in Weinstein 1980, cited in Frewer et al., 2003) by a disease, perceived functional foods as irrelevant to them. Nevertheless, the same participants reported being able to understand how others with a similar health issue as the one promised can well find the use of functional foods 
justified 'I think...like when someone is having a health problem I think they are more likely to consume... if they have fragile bones, they might buy XXX with added calcium a bit more easily.. and yes I might end up consuming a product if I find it will help me' $(10$, F , 25-39). It has been proven that the more people are feeling at risk of a specific disease, the easier it is to adopt relevant healing behaviour (Mckenna, 1993), a statement in total agreement with the findings of this study.

\section{$\underline{\text { Final Appraising }}$}

Although the appraising process is presented as the final one of a long procedure, it should not be perceived as such. It should be clear by now that all of the elements of the proposed framework are interacting, providing a more or less simultaneous appreciation of the situation for consumers final choices. This stage is more of a representation of how people integrate all of their aforementioned beliefs in order to build a depiction of each functional food and reach their final decisions. At the same time consumers' form their level of 'resistance' to increasing marketing influences and perceptions of pricing.

Marketing Influences: Consumers are confronted with an abundance of advertisement and marketing offers more than ever before. It is the case that they perceive themselves and especially others more vulnerable to advertisement and TV influence than one can foresee. Special offers like BOGOF (Buy One Get One Free) $(10, \mathrm{~F}, 25-39)$ or price reduction mechanisms (4, F, 40-59) have been frequently reported. In addition, packaging and general product liking can influence decisions as already indicated: 'if I fancied it, I would buy it because I like the look of it not because it was gonna help this or that' (4, F, 40-59). Marketing activities act as 
external influences which can induce people to circumvent the rest of their prevalent ideas and perceptions.

Monetary Issues: Financial factors, and more importantly price, were recognised as one of the central factors of functional foods choices. Functional products were described by all participants as 'dearer' than all other brands and their pricing was perceived as one of the aspects that can negatively influence consumer choices. Several participants (4, F, 40-59; 7, F, over 60; 10, F, 25-39; 12, F, 25-39; 13, M, 40-59) explained that they would be willing to use functional products more often if functional products were offered in the market with a more reasonable price: 'if prices were more on par with regular products, myself and other people would be perhaps more inclined to give them a try or consume them more regularly' (4, F, 4059). It is also relevant to indicate that consumers in several cases admitted that the idea that functional foods are expensive stems from everyday price comparisons and not from participants' mere impressions.

In addition, participants indicated that it is not only pricing as an objective characteristic that influenced them. The perceived worth of functional foods is another important element of the process. Pricing was evaluated differently by each participant depending on his/ hers position on the rest of the elements of the framework. For example, although functional foods were considered 'dearer' by all participants, in those cases that participants valued their worth highly in their food system (5, F over $60 ; 2$, F , 40-59) they were prepared to pay that little extra: 'If I found a yoghurt relevant to me then yea...maybe then its' worth it to pay that little extra' (4, F, 40-59). 
It could be argued that financial issues could well fit within the previous 'marketing' influences' category. The decision to befall into a category on its own was based on the observation that pricing issues were mentioned at least two times in each of the 15 interviews.

\section{DISCUSSION AND IMPLICATIONS}

\section{Theoretical Implications}

Consumers' decision making in terms of functional foods' choices can be considered a complex process. Three decision- making levels have been identified each of which contributes to consumer choices. This process, as described and evaluated above, has been an effort to arrive at some overall understanding of the interplay among various types of influences and has provided new insights, proliferated by the 'holistic' qualitative approach. This framework should however, considered a proposal of a broad process and only meant to be suggestive and not conclusive; thus should be treated accordingly.

A key conclusion of this analysis is that when consumers consider the choice of functional foods they seem to be entangled with notions related to psychological benefits, importance, price, and at an abstract level with what is defined as acceptable (healthy) eating. The interviewed industry experts also identified several of the elements, especially of the self-relevant motivation and price as main reasons underlying decisions to use functional products. More specifically 'guilt and fear' for other food related choices or for merely not doing 'the best for oneself' has been placed at the core of consumer decision- making by all marketing experts (Experts 2, 3 and 4). 
In the present study, functional products were described using a definition and several stimuli products in order to help participants develop a common understanding of the category. Interestingly, there is no unique definition of what a functional food is. This definitional issue is in part a reflection of the difficulty of defining food that is healthy, which is in itself a complex issue (Butrriss, 2010). Despite this lack of precision about what constitutes a functional food, the present study managed to combine the widely adopted working definition from Diplock et al. (1999) with several other reports and test its acceptability by the food industry. A consensus then is not impossible and it requires the collaboration between the scientific community and the food industry.

Protection motivation theory (Roger, 1975) and previous research (Cox et al., 2004) have identified perceived efficacy of actions connected to health communications and functional products as an important dimension of consumer choice. However in the present endeavour no such prominence was identified. Contrary, perceived efficacy was found to be overpowered by other motivational factors like for example consumers' perceived need of a specific functional food or general trust towards the industry. Taking into consideration the fact that Cox et al. (2004) study was based on imaginary products targeting memory loss, consumers might consider efficacy as an important parameter of such 'potential' but not actual choices. When the same question is placed within the framework of their actual choices it seems to be suspended by other considerations. In addition, other studies (Urala and Lähteenmäki, 2003, 2007; Verbeke, 2005) treated perceived efficacy as part of a more general attitudinal construct, that of 'confidence in functional foods' (Urala and Lähteenmäki, 2003) or 'health benefit belief' (Verbeke, 2005) and thus the intention was to assess a more general construct rather than efficacy per se. 
In order to summarise the research findings and direct future research a number of propositions have been formed which directly stem from the suggested framework:

Proposition 1: Functional foods are placed and assessed within the wider healthy eating system of consumers.

Proposition 2: Consumers perceptions of healthy eating do not directly influence consumers' choices of FF as suggested by previous literature. Rather, this relationship is moderated by a 'benefit' negotiation process.

Proposition 3: The way consumers shape functional foods' choices is reliant upon two different kinds of factors namely: pragmatic and psychological aspects formed by them.

Proposition 4: These factors form both the final appraisal of functional foods and the final choice between different product types.

Proposition 5: Price is one of the most important dynamic factors identified to influence consumer choices.

Proposition 6: The perceived efficacy of functional foods is shaped through consumers' consumption motivation and perceived importance and in that sense it should play limited role in consumers' actual decision-making.

Proposition 7: Consumers' choices of functional foods seem to have a dynamic of continually changing based on evolving individual motivations, facts of life and the messages of the social and environmental network (e.g. what can be perceived as healthy eating).

\section{Managerial Implications}


From a managerial perspective understanding the concept and reasons for acceptance of health claims is a crucial task. The concepts of healthy eating, detox marketing, organic foods, vegan eating habits, and functional foods encourage a healthy lifestyle, becoming very popular terms that preoccupy food managers' time and effort. This study provides directions for the utilisation of appropriate marketing strategies and public policies for the types of foods that have been called as functional.

The key points stemming from the experts' discussions are summarised below. Industry experts identified the key functional food consumption motivation as in the participants' discourse. Aspects like guilt, compensation for other food choices, use of functional foods to target specific health problems, trust towards brands and age are aspects recognised by them. Another important observation regarding functional products is that the majority of negative attitudes concerned the fact that such commodities seem to be one more attempt ('marketing gimmick') of the food industry to increase profits and sales. The most interesting part however is that industry experts also tended to hold a parallel position. Their point was that such products are not deprived from real health value but simultaneously have been mainly developed as a new category that provides great potentials of enhanced profitability. Functional foods, with their unique characteristic of promising health and wellbeing, could act as a very interesting context upon which a debate over the long lasting controversy over marketing 'finding or creating needs' could be reignited.

The analysis mainly indicated that the way consumers perceived the benefits of functional foods is subject to modifications through the changing life circumstances of participants (e.g. changing health conditions, age or perceptions of healthy eating) and are also influenced by marketing promotions. It could be then 
claimed that several aspects of this framework (e.g. perceptions of healthy eating and their links to motivation) can be well influenced by proper targeting and communication.

The fact that consumers consume functional foods to counteract for other unhealthy choices is detrimental to their wellbeing. This means that they can use these types of foods out of guilt, as a way to clear other unhealthy choices. Such emotional aspects like easing guild or increased feelings of worthiness are very good candidates when developing promotional campaigns. This study will not encourage such marketing actions but would contrary argue that policy makers (who strive for the promotion of a healthy lifestyle) should be wary of this reality and aim to develop more effective healthy eating campaigns. These healthy eating campaigns should explain the nature of functional foods and indicate that these should be used as part of a healthy diet but not replace one.

Self- related importance plays a crucial role when it comes to the motivation to consume functional products thus targeting and positioning of such products is possibly the most important marketing step that companies can take. Since perceived efficacy is not a detrimental factor, companies can influence consumers with the correct positioning of products.

Finally, on the topic of perceived efficacy, two further points bear implications for managers. To start with, consumers seem to base their decisions on trust towards policies and the food industry in general (for example 'they cannot claim something if it is not true'). Industry expert 2 has commented on brand trust as a crucial component of the decision-making process of consumers. Food policy organisations and companies have a strong responsibility when it comes to the introduction of food quality rules and industry communications in order to avoid 
diminishing their credibility and as a consequence diminishing consumer trust. The second consequence is related to the processing that is taking place in high vs low efficacy situations. Since consumers are likely to place less emphasis on processing situations when they believe in the high efficacy of such products (functional foods seem to be a case where consumers 'convince' themselves of the efficacy of such products), functional foods are likely to be bought without much effort or consideration placed in the decision making. This might imply that healthy and unhealthy options of functional foods might be chosen irrespective of their health consequences. Especially food policy organisations have a responsibility to train consumers on the differences among different products and claims and assist consumers understand that not all functional food choices are for their benefit.

\section{LIMITATIONS AND FUTURE RESEARCH}

Every effort has been taken so that the results are reasonable and suggestive indicators of the complexity of the studied phenomenon. The crucial steps have been the identification of any possible biases along with a clear detailing of methods of data collection, analysis along with the adequate description and identification of participants. In order to ensure the trustworthiness and accuracy of techniques and data collection procedures, data was gathered in different forms: the transcribed data, directly taken field notes from interviews, extended notes and memos made as soon as possible after the field work. There was also a constant dynamic relationship between data collection and analysis which allowed control over the constancy of categories developed.

Nevertheless, due to the use of specific stimuli in this study, participants' narratives tended to focus more on these four specific products. This threat to results 
was acknowledged very early during the research process; nevertheless, a lack of stimuli which could possibly lead to a vague conceptualisation of functional foods or to a lack of a reference point, possibly hindering the flow of discussions, was evaluated as more threatening to this study than the use of representative products. Future studies could then focus on specific categories or product claims.

Future research directions can be developed through the comparison of the elaborate literature review and the understanding developed through this research (Fig. II). The form of previous research can find support through this qualitative approach and the previous attitudinal exploration of functional foods has provided some understanding of the factors identified in this research. However, three central ideas deserve further elaboration and attention: 1. the positioning of functional foods in consumers' healthy eating system, 2 . the role of perceived efficacy and 3 . the influence of pricing issues on consumers' perspectives of functional foods.

To start with, the perceptions towards healthy eating and the ways functional foods fit within this system of healthiness deserve further investigation. Although recent studies have examined the way claims influence perceptions of overall product healthiness (e.g. Saba et al., 2010), this study corroborates mainly with Niva (2007) in the sense that consumers have been found to place and assess functional foods within the boundaries of a more holistic healthy diet. However it has been beyond the scope of this study to examine this issue in more detail and Niva's study (2007) suffers from several restrictions of sampling (wealthy, health- oriented Finns) and limited products examined (cholesterol lowering spreads only), so more studies are required.

Monetary issues and more specifically price were recognised among the most important dynamics that influence final decisions to select functional products by both experts (2, 3 and 4) and consumers. Even though, the majority of the functional food 
consumer literature ignores aspects of pricing in order to investigate more abstract psychological concepts, the significance of pricing should not be neglected.

According to this study price can well act as the point where intentions or willingness to consume are translated (or not) into actual behaviour. As some consumers might attribute the current increased cost of functional foods to marketing practices and not actual value, it becomes evident that some of the negative attitudes and motivations identified have their roots in pricing issues. It would be meaningful to further experimentally investigate, whether a massive reduction in the prices of functional foods, as suggested by the participants of this research, would indicate increased sales or rather a further negative change of consumers' perceived quality and efficacy of such products.

Finally, more research is required on functional foods' perceptions of efficacy in order to assess its role in final choices. The literature remains inconclusive on its role on functional food choices and a better examination of this widely applied in medicine and health marketing concept (Block \& Keller, 1995) requires further exploration.

\section{CONCLUSION}

This research reiterates the significance of several factors when it comes to understanding the dynamics of consumer decision-making in a complex substantive area such as functional foods. The findings of the study point towards a general acceptance of the concept of functional foods by consumers. Placed within the wider framework of a healthy lifestyle and eating habits, the choices of functional foods seem to be determined by aspects that can be influenced by appropriate marketing actions. Although clearly having the core characteristics of foods, i.e. taste, quality, 
pricing, their main element is that these have specific nutritional claims that consumers believe based on grounds beyond the actual efficacy of the products. 


\section{References}

Anderson AS, Cox DN, McKellar S, Reynolds J, Lean ME, Mela DJ. (1998), Take Five, a nutrition education intervention to increase fruit and vegetable intakes: impact on attitudes towards dietary change. British Journal of Nutrition 80: 133-140.

Annunciata A, Vecchio R. (2011), Functional foods development in the European market: A consumer perspective. Journal of Functional Foods 3: 223-228.

Anttolainen M, Luoto R, UUtela A, Boice J, Blot W, McLaughlin J, Puska P, et al. (2001), Characteristics of users and non users of plant stanol ester margarine in Finland: An approach to study functional food. Journal of the American Dietetic Association 101: 1365-1368.

Ares G, Gambaro A. (2007), Influence of gender, age and motives underlying food choice on perceived healthiness and willingness to try functional foods. Appetite 49: 148-158

Ajzen I. (1985), From intentions to actions: A theory of planned behavior. In J. Kuhl and J. Beckmann (Eds.), Action control: From cognition to behavior (p.1139). Berlin, Heidelber, New York: Springer-Verlag.

Barrios XD, Bayarri S, Carbonell I, Izquierdo L, Costell E. (2008), Consumer attitudes and opinions towards functional foods: A focus group study. Journal of Sensory Studies 23: 514-525.

Bardi A, Schwartz SH. (2003), Values and behaviour: Strength and structure of relations. Personality and Social Psychology Bulletin 29: 1207-1220.

Bech-Larsen T, Grunert KG. (2003), The perceived healthiness of functional foods. A conjoint study of Danish, Finnish and American consumers' perception of functional foods. Appetite 40: 9-14. 
Bech-Larsen T, Scholderer J. (2007), Functional foods in Europe: Consumer research, market experiences and regulatory aspects. Trends in Food Science and Technology 18: 231-234.

Berger P, Luckman T. (1966), The social construction of reality. Garden City: Doubleday.

Bhaskaran S, Hardley F. (2002), Buyer beliefs, attitudes and behaviour: foods with therapeutic claims. The Journal of Consumer Marketing 19: 591-606.

Block, L. G., Keller, P. A. (1995), When to accentuate the negative: The effects of perceived efficacy and message framing on intentions to perform a healthrelated behavior. Journal of Marketing Research 32 (2): 192-203.

Bitzios M, Frazer I, Haddock, FJ. (2011), Functional ingredients and food choice: Results from a dual-mode study employing means-end-chain analysis and a choice experiment. Food Policy 36: 714-724.

Butrriss JL. (2010), Are health claims and functional foods a route to improving the nation's health? Nutrition Bulletin 35: 87-91.

Chaiken S, Pliner P. (1987), Women, but not men, are what they eat: the effect of meal size and gender on perceived femininity and masculinity. Personality and Social Psychology Bulletin 13: 166-176.

Charmaz K. (2003), Grounded theory: Objectivist and constructivist methods. In N.K. Denzin and Y.S. Linkoln (eds.), Strategies of Qualitative Inquiry (pp. 249-291). London: Sage.

Childs NM, Poryzees GH. (1997), Foods that help prevent disease: consumer attitudes and public policy implications. Journal of Consumer Marketing 14: $433-448$. 
Chylinski M, Chu A. (2010), Consumer Cynicism: antecedents and consequences. European Journal of Marketing 44: 796-837.

Corbin J, Strauss A. (2008), Basics of Qualitative Research: Techniques and Procedures for Developing Grounded Theory, London: Sage.

Cornish SL. (2012), It's good for me: It has added fibre! An exploration of the role of different categories functional foods in consumer diets. Journal of Consumer Behaviour 11: 292-302.

Cox DN, Koster A, Russell CG. (2004), Predicting intentions to consume functional foods and supplements to offset memory loss using an adaptation of protection motivation theory. Appetite 43: 55-64.

Crawford P, Brown B, Nerlich B, Koteyko N. (2011), Nutritional altruism and functional food: lay discourses on probiotics. Sociology of Health and Illness 32: $745-760$.

De Jong N, Ocké MC, Branderhorst HAC, Friele R. (2003), Demographic and lifestyle characteristics of functional food consumers and dietary supplement users. British Journal of Nutrition 89: 273-281.

Diplock AT, Aggett PJ, Ashwell M, Bornet F, Fern EB, Roberfroid MB. (1999), Scientific concepts of functional foods in Europe: Consensus document. British Journal of Nutrition 81 (Suppl.1): S1-S27.

Fishbein M, Ajzen I. (1975), Beliefs, Attitudes, Intention and Behaviour: an introduction to theory and research, New York: Wiley and Sons.

Flick U. (2009), An Introduction to Qualitative Research. $4^{\text {th }}$ edition, London: Sage. Frewer L, Sholderer J, Lambert N. (2003), Consumer acceptance of functional foods: issues for the future. British Food Journal 10: 714-731. 
Furst T, Connors M, Bisogni CA, Sobal J, Falk LW. (1996), Food choice: A conceptual model of the process. Appetite 26: 247-266.

Gardner DM. (1970), An experimental investigation of the price-quality relationship. Journal of Retailing 46 (Fall): 25-41.

Glasser B, Strauss A. (1967), The Discovery of Grounded Theory, Chicago: Adeline. Glaser, B. (1978), Theoretical Sensitivity: Advances in the Methodology of Grounded Theory. California: Sociology Press.

Gleicher, F, Petty, RE. (1992), 'Expectations of reassurance influence the nature of fear stimulated attitude change', Journal of Experimental Social Psychology $28,86-100$.

Grunert GK. (1995), Food quality: a means-end perspective. Food Quality and Preferences 6: 171-176.

Grunert GK, Scholderer J, Rogeaux M. (2011), Determinants of consumer understanding of health claims. Appetite 56: 269-277.

Gutman J. (1982), A means-end chain model based on consumer categorization processes. Journal of Marketing 46: 60-72.

Hair J, Bush R, Ortinau D. (2006), Marketing research within a changing environment. $3^{\text {rd }}$ edition. New York: McGraw- Hill.

Herath D, Cranfield J, Henson, S. (2008), Who consumes functional foods and nutraceuticals in Canada? Results of cluster analysis of the 2006 survey of Canadians' Demand for Food Products Supporting Health and Wellness. Appetite 51: 256-265.

Huotilainen A, Pirtilla-backman AM, Tuorila H. (2006), How innovativeness relates to social representations of new foods and the willingness to try and use such foods. Food Quality and Preference 17: 353-361. 
ILSI Europe. (2002), Concepts of functional foods. ILSI Europe Concise Monograph Series. Belgium.

Jonas SJ, Beckmann S. (1998), Functional foods. Consumer perceptions in Denmark and England, MAPP Working Paper no 55, The Aarhus School of Business, Aarhus.

Krystallis A, Maglaras G, Mamalis S. (2008), Motivation and cognitive structures of consumers in their purchasing of functional foods. Food Quality and Preference 19: 525-538.

Kvale, S. (1996), InterViews: An introduction to qualitative research interviewing. Sage: California.

Lähteenmäki L, Lampila P, Grunert K, Boztug Y, Ueland Ø, Aström A, Martinsdottir E. (2010), Impact of health-related claims on the perception of other product attributes. Food Policy 35: 230-239.

Landström E, Koivisto Hursti UK, Magnusson M. (2009), 'Functional foods compensate for an unhealthy lifestyle'. Some Swedish consumers' impressions and perceived need of functional foods. Appetite 53: 34-43.

Maddux, J., Rogers, R. (1983), 'Protection motivation and self-efficacy: A revised theory of fear appeals and attitude change'. Journal of Experimental Social Psychology, 19, 469-479.

Maitlis, S. (2005), The social process of organisational sensemaking. The Academy of Management Journal, 48(1), 21-49.

McKenna FP. (1993), It won't happen to me: unrealistic optimism or illusion of control? British Journal of Psychology 84: 39-50.

Mintel Report (2013), Consumer attitudes toward functional food and drink -UK. February. 
Moliner P, Tafani E. (1997), Attitudes and social representations: a theoretical and experimental approach. European Journal of Social Psychology 27: 687702.

Murphy E, Dingwall R. (2003), Qualitative Methods in Health Policy Research, New York: Aldine Transaction.

Niva M. (2007), 'All foods affect health': Understandings of functional foods and healthy eating among health-oriented Finns. Appetite 48: 384-393.

O'Connor EL, White KM. (2010), Willingness to trial functional foods and vitamin supplements: The role of attitudes, subjective norms, and dread of risk. Food Quality and Preference 21: 75-81.

Oxoby RJ., Finnigan, H. (2007), Developing heuristic- based quality judgements: Blocking in consumer choice, Psychology and Marketing, 24 (4): 295- 313.

Patch CS, Tapsell CL, Williams GP. (2005a), Overweight consumers'salient beliefs on omega-3-enriched functional foods in Australia's Illawarra region. Journal of Nutrition Education and Behaviour 37: 83-89.

Patch CS, Tapsell CL, Williams GP. (2005b), Attitudes and intentions toward purchasing novel foods enriched with Omega-3 fatty acids. Journal of Nutritional Education and Behaviour 37: 235-241.

Pliner P, Hobden K. (1992), Development of a scale to measure the trait of food neophobia in humans. Appetite 19: 105-120.

Rogers, R. W. (1975), ‘A Protection Motivation Theory of Fear Appeals and Attitude Change', The Journal of Psychology, 91, 93-114.

Saba A, Vassallo M., Shepherd R, Lampila P, Arvola A, Dean M, Winkelmann M, Claupein E, Lähteenmäki L. (2010), Country-wise differences in perception of health-related messages in cereal-based food products. Food Quality and Preference 21, 4: 385-393. 
Saher M, Arvola A, Lindeman M, Laahtenmaki L. (2004), Impressions of functional food consumers. Appetite 42: 79-89.

Siegrist M, Stampfli N, Kastenholz H. (2008), Consumers' willingness to buy functional foods. The influence of carrier, benefit and trust. Appetite 51: $526-529$.

Siro I, Kapolna E, Kapolna B, Lugasi A. (2008), Functional food. Product development, marketing and consumer acceptance- A review. Appetite 51: $456-467$.

Stevenson FA, Britten N, Barry CA, Barber N, Bradley CP. (2000), Qualitative methods and prescribing research. Journal of Clinical Pharmacy Therapeutics 25: 317-324.

Tanner, JF Jr, Hunt, JB, \& Eppright, DR. (1991), 'The Protection Motivation Model: A Normative Model of Fear Appeals', Journal of Marketing 55 (3), 36-45.

Urala N, Lähteenmäki L. (2003), Reasons behind consumers’ functional food choices. Nutrition and Food Science 33: 148-158.

Urala N, Lähteenmäki L. (2004), Attitudes behind consumers' willingness to use functional foods. Food Quality and Preference 15: 793-803.

Urala N, Lähteenmäki L. (2007), Consumers' changing attitudes towards functional foods. Food Quality and Preference 18: 1-12.

Lähteenmäki L, Lampila P, Grunert K, Boztug Y, Ueland Ø, Åström A, Martinsdóttir E. (2010), Impact of health related claims on the perceptions of other product attributes. Food Policy 35: 230-239.

van Kleef E., van Trijp HCM, Luning P. (2005), Functional foods: Health claim food product compatibility and the impact of health claim framing on consumer evaluation. Appetite 44: 299-308. 
Van Trijp HCM, van der Lans IA. (2007), Consumer perceptions of nutrition and health claims. Appetite 48: 305-324.

Verbeke W. (2005), Consumer acceptance of functional foods: socio-demographic, cognitive and attitudinal developments. Food Quality and Preference 16: 4557.

Weiner K. (2011), The subject of functional foods: accounts of using foods containing Phytosterols. Sociological Research online 16: 7. 
Figure I. Development of a new conceptual framework relevant to functional food choices. Source: this research.

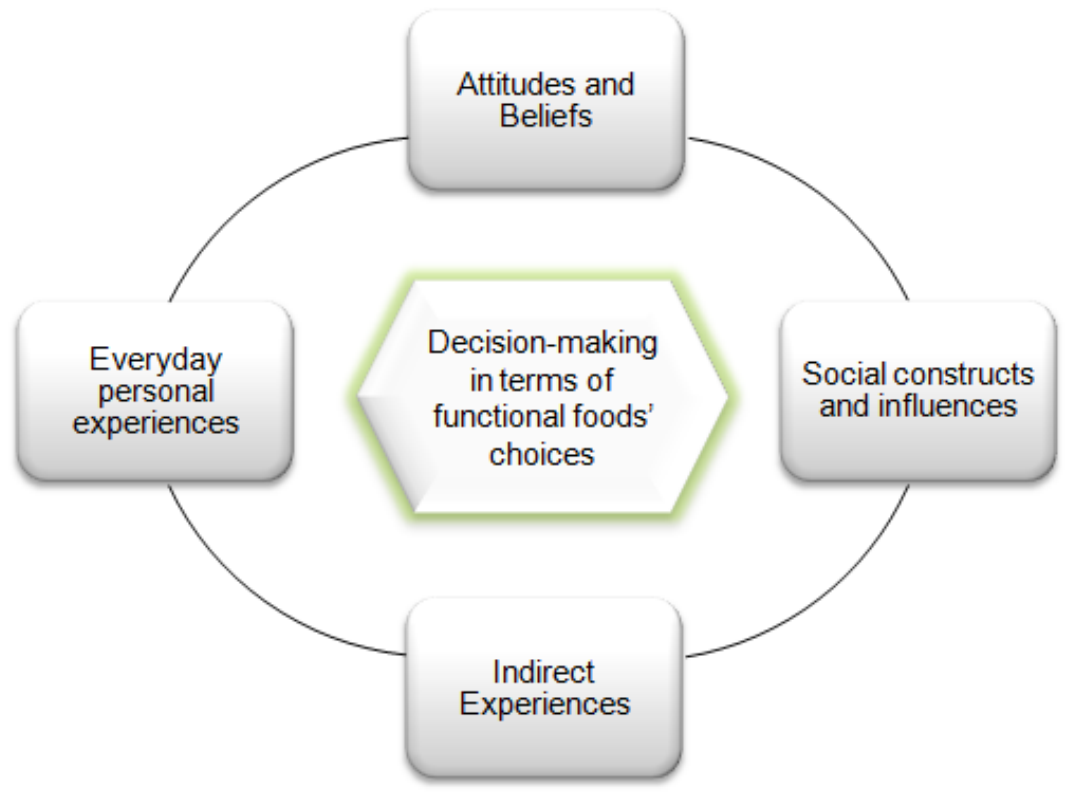




\begin{tabular}{|c|c|c|c|c|c|c|}
\hline & Participants & $\begin{array}{c}\text { Classification } \\
\text { (Gender, Age } \\
\text { Group) }\end{array}$ & Employment & $\begin{array}{c}\text { Number of } \\
\text { people in } \\
\text { household }\end{array}$ & $\begin{array}{c}\text { Food } \\
\text { purchase } \\
\text { primary } \\
\text { decision } \\
\text { maker }\end{array}$ & $\begin{array}{c}\text { Spontaneous } \\
\text { knowledge } \\
\text { of the term } \\
\text { 'Functional } \\
\text { Foods' }\end{array}$ \\
\hline \multirow{7}{*}{$\begin{array}{l}\text { Routine } \\
\text { users- of } \\
\text { at least- } \\
\text { one } \\
\text { functional } \\
\text { food }\end{array}$} & Participant 1 & $(\mathrm{M}, 25-39)$ & Executive & 1 & Yes & Yes \\
\hline & Participant 2 & $(F, 40-59)$ & Office clerk & 1 & Yes & No \\
\hline & Participant 3 & $(\mathrm{M}$, over 60$)$ & Pensioner & 1 & Yes & No \\
\hline & Participant 4 & $(\mathrm{~F}, 40-59)$ & Office clerk & 4 & Yes & No \\
\hline & Participant 5 & $(\mathrm{~F}$, over 60$)$ & Office clerk & 2 & Yes & No \\
\hline & Participant 6 & $(\mathrm{~F}, 25-39)$ & Student & 1 & Yes & Yes \\
\hline & Participant 7 & $(\mathrm{~F}$, over 60$)$ & Office clerk & $\begin{array}{l}2 \text { (+grand- } \\
\text { children } \\
\text { visiting often) }\end{array}$ & Yes & No \\
\hline \multirow{8}{*}{$\begin{array}{l}\text { Non users } \\
\text { of } \\
\text { functional } \\
\text { foods }\end{array}$} & Participant 8 & $(\mathrm{~F}, 40-59)$ & Office clerk & 1 & Yes & No \\
\hline & Participant 9 & $(\mathrm{M}, 25-39)$ & Office clerk & 2 & No & No \\
\hline & $\begin{array}{l}\text { Participant } \\
10\end{array}$ & $(\mathrm{~F}, 25-39)$ & Office clerk & 4 & Yes & No \\
\hline & $\begin{array}{l}\text { Participant } \\
11\end{array}$ & $(F, 40-59)$ & Office clerk & 2 & Yes & No \\
\hline & $\begin{array}{l}\text { Participant } \\
12\end{array}$ & $(\mathrm{~F}, 25-39)$ & Office clerk & 3 & No & No \\
\hline & $\begin{array}{l}\text { Participant } \\
13\end{array}$ & $(\mathrm{M}, 40-59)$ & Executive & 2 & $\begin{array}{c}\text { Yes } \\
\text { (together } \\
\text { with } \\
\text { spouse) } \\
\end{array}$ & Yes \\
\hline & $\begin{array}{l}\text { Participant } \\
14\end{array}$ & $(\mathrm{~F}, 25-39)$ & Housewife & 3 & Yes & Yes \\
\hline & $\begin{array}{l}\text { Participant } \\
15\end{array}$ & $(\mathrm{~F}, 25-39)$ & Teacher & 3 & No & No \\
\hline
\end{tabular}

Table I. Characteristics of study participants. Source: this research. 
Table II: Stages of data analysis. Source this research.

\begin{tabular}{|c|c|c|}
\hline \multicolumn{3}{|c|}{ Stages of Data Analysis } \\
\hline Stage & Action & Example \\
\hline $\begin{array}{l}\text { Stage 1. Open } \\
\text { coding: Develop an } \\
\text { understanding of the } \\
\text { data and coding }\end{array}$ & $\begin{array}{ll}\checkmark & \text { Active re-readings of transcriptions } \\
\text { (incl. memos and other notes) } \\
\checkmark \text { Coding of categories } \\
\checkmark \text { Deciding rules for inclusion of an } \\
\text { open code category: } \\
>\text { An issue had to be arisen in the } \\
\quad \text { discourse of at least } 7 \text { participants } \\
\text { to be accepted as a theme (for a } \\
\text { similar approach see Maitlis, } \\
\text { 2005). } \\
>\text { Brief definitions of codes were } \\
\text { formed so that the categorisation } \\
\text { of text in a code is facilitated. }\end{array}$ & $\begin{array}{l}\text { Identification of basic concepts like: } \\
\text { age, gender, psychological motives } \\
\text { etc. } \\
\text { Examples of definitions formed: } \\
\text { Age: Information relating to age (no } \\
\text { matter if it is referring to self or } \\
\text { other). } \\
\text { Self-related motives: Any } \\
\text { information that relates to } \\
\text { consumption motives and reasons. }\end{array}$ \\
\hline $\begin{array}{l}\text { Stage } 2 \text {. Axial } \\
\text { coding: Finding the } \\
\text { relationships, } \\
\text { connections and } \\
\text { overarching } \\
\text { concepts/ themes. }\end{array}$ & $\begin{array}{l}\checkmark \text { Identify connections and links } \\
\text { through consumers' discourse. } \\
\checkmark \text { Place and identify (through } \\
\text { judgement) elements of the decision- } \\
\text { making that form the decision-making } \\
\text { process. }\end{array}$ & $\begin{array}{l}\text { Example: the open code 'healthy } \\
\text { eating values' cannot correspond as } \\
\text { an active part of a decision-making } \\
\text { process thus the decision-making } \\
\text { level had to be identified. In this case } \\
\text { it has been 'the abstract level of } \\
\text { decision-making' - a process where } \\
\text { consumers form a general } \\
\text { understanding of what healthy eating } \\
\text { is and place functional foods within } \\
\text { this understanding- text that indicates } \\
\text { that: 'if you have a balanced diet you } \\
\text { don't really need them' } \\
\text { 'although I do not have a problem } \\
\text { like those promised, I believe that it } \\
\text { is probably better to consume those } \\
\text { than ... other rubbish I tend to } \\
\text { consume' }\end{array}$ \\
\hline $\begin{array}{l}\text { Stage 3. Selective } \\
\text { coding: Core theme }\end{array}$ & $\begin{array}{l}\checkmark \text { Analysis of all the themes focusing on } \\
\text { the core element. This is central and } \\
\text { connects the story in the data. } \\
\checkmark \text { Rules for the identification of the core } \\
\text { theme: } \\
>\text { Some aspect mentioned by all the } \\
\text { participants. } \\
>\text { Central route that all participants } \\
\text { understand as central. }\end{array}$ & $\begin{array}{l}\text { The benefit negotiation process has } \\
\text { been identified as a key process, (this } \\
\text { is not to say that consumers base } \\
\text { their final decisions on this step only } \\
\text { but mainly to say that this step is } \\
\text { taking place for all of the } \\
\text { respondents of this study.) }\end{array}$ \\
\hline
\end{tabular}


Figure II. Decision- Making Framework (everyday thinking in terms of functional foods). Source: this research.

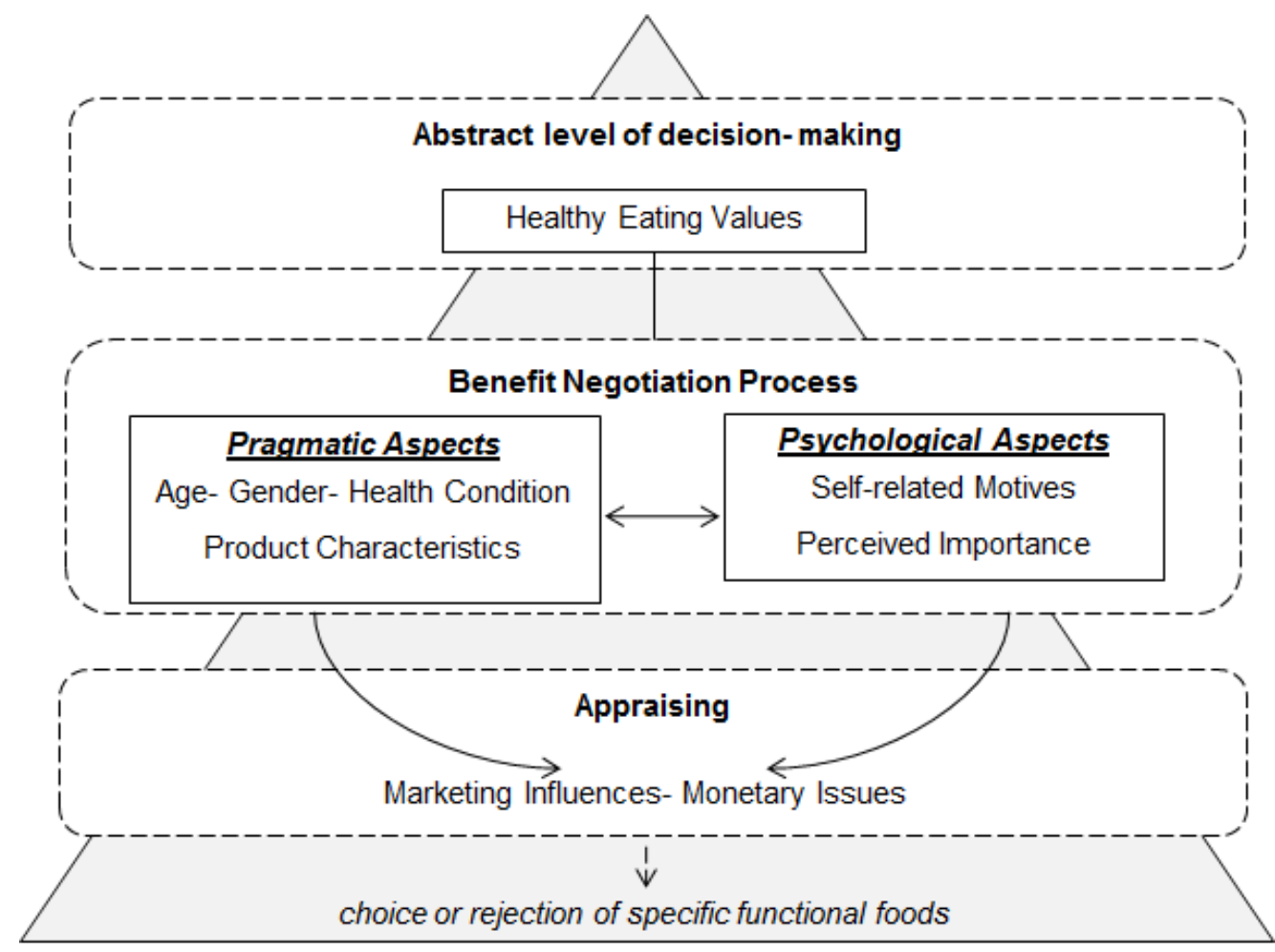

